AUTUOR'S ABSTRAT OF THIS PAPER ISSURD HY THE BIBLIOGRAPHIC SERVICE, APRIL 7

\title{
THE CORACOID OF SUS SCROFA
}

\author{
FRANK BLAIR HANSON \\ Zoological Laboratory of Washington University \\ SIX FIGURES
}

The problem of the coracoid is one of the unsolved questions of vertebrate morphology. Its homologies have been described from every possible viewpoint, yet there remains to-day as much confusion and divergence of opinion concerning this structure as in any past period.

This paper is unlike most in that it does not attempt to offer a new solution of the old problem. It is a description of the developmental stages of the subcoracoid as found in the pig. The material consists of a series of seven scapulae ranging in age from three weeks to adult life and a fairly complete series of sections of embryonic stages. No embryonic stages are figured, for in general they are not essentially different from figure 1 of the suckling pig.

Although the coracoidal part of the pig scapula is never a separate cartilage, it may be identified as early as the $26-\mathrm{mm}$. stage of the embryo as a distinct, but blunt knob, on the anterior side of the glenoid surface. This is not, however, separated from the cartilage of the glenoid, but is continuous with it, and is a constituent part of the articular surface. Following the history of this portion through close stages of the embryonic and foetal life discloses no essential change of relations or appearance until we pass from foetal to postnatal life. Figure 1 is the glenoid end of the scapula of a pig two weeks old. The relatively large cap of cartilage is one homogeneous whole, and has been so since first recognizable in the embryo. The shaft of the scapula has been cut in the median plane in an anterior-posterior direction, as have also the other stages herein illustrated. Figure 2 is the scapula of a pig three months of age. During 197 

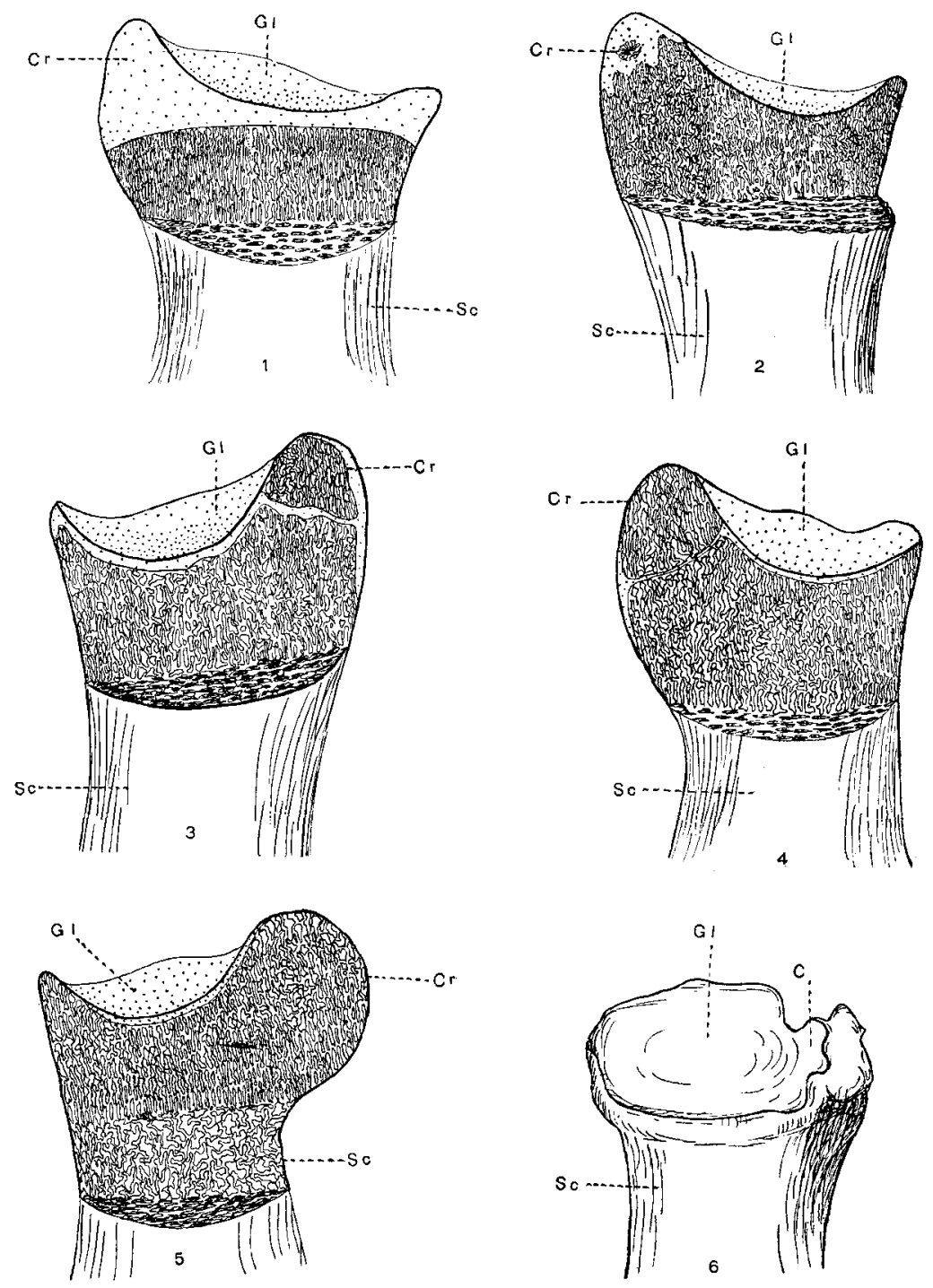
the interval since the first stage figure, the center of ossification for the coracoid has appeared. It lies in the center of the coracoid cartilage, and it will be noticed that the ossification of the scapula has proceeded rapidly toward the glenoid end, leaving only a thin sheet of cartilage over the articular surface and the cartilage of the coracoid surrounding its ossific center.

Figures 3 and 4 are of one-half and three-quarters grown pigs, respectively. They show the growth of the ossific center and its encroachment upon the cartilage of this region. The pig of figure 4 is approximately nine months of age, and there remains but a narrow layer of cartilage between the scapula and coracoid. The cartilage of the glenoid surface has been further reduced. Figure 5 is that of a fully matured hog. This specimen weighed 450 pounds and evidently was past what might be termed young adult life. Sections through the glenoid-coracoid region of this bone fail to show any trace of the fusion of the coracoid with the scapula. It is to all appearance one solid bone, and not knowing its early history one would not suspect that this had been two separate bones until young adult life. In figure 6 is shown the glenoid portion of a scapula from a pig one year old. It gives a good conception of the general appearance and relations of coracoid and glenoid parts. Fully one-fourth of the glenoid is composed of the coracoidal contribution.

The coracoid here described is not the coracoid process of placental mammals, but that smaller, more inconspicuous element known in man as the subcoracoid. The coracoid of the

Fig. 1 Pig 3 weeks old. Glenoid end of scapula. No ossific center for subcoracoid. $\times 7$.

Fig. 2 Pig 3 months of age. Center of ossification present. $\times 3$.

Fig. 3 Pig one-half grown. Subcoracoid a separate bone from scapula. $\times 3$.

Fig 4 Pig three-fourths grown. Coalescence of subcoracoid and scapula nearing completion. $\times 2$.

Fig. 5 Scapula of old boar. All trace of fusion of subcoracoid and scapula lost. $\times 1$.

Fig. 6 Young adult, one year old. Articular surface made up of three-fourths scapula and one-fourth coracoid. $\times 1$.

ABBREVIATIONS

$$
C r . \text { subcoracoid } G l ., \text { glenoid } S c ., \text { scapula }
$$


Suidae is a so-called subcoracoid and is undoubtedly the homologue of that structure bearing the same name in man. Both are glenoid-sharing portions, and in all the details of general topography are identical.

In mammals bearing a coracoid process two centers of ossification are present-one for the coracoid process and one for the subcoracoidal, glenoid part. In the pig but one ossific center, that of the subcoracoid, is found. The pig scapula is degenerate, lacking both coracoid process and acromium.

Broom ('99) was the first to suggest that the so-called subcoracoid was merely an epiphysis, and did not enter into the coracoid problem. Gregory ('15) disputes Broom on this point and agrees with Williston that this so-called epiphysis is really the metacoracoid, and a reptilian inheritance. In a later paper, however, Gregory ('17 a) reverses this conclusion and admits that Broom may be correct and that this is merely an epiphysis. And still later in the same year, he (Gregory, '17 b) was led to believe that this subcoracoid is not merely an epiphysis, but the epiphysis of the glenoid portion of the metacoracoid or true coracoid. Gregory thus derives both coracoid process and subcoracoid from the true or posterior coracoidal element. The anterior or epicoracoidal part has been completely reduced and is not represented in placental mammals.

On the other hand, Cunningham ('16) homologizes the coracoid process with the epicoracoid, and the subcoracoid with the posterior (meta) coracoid. This is also the position taken by Lydekker ('93), Howes ('93), Williston, and others.

That Gregory may be more nearly correct than the other workers is indicated in the progressive shutting out of the epicoracoid (anterior element) from any share in the glenoid. This proceeds as we ascend higher in the scale, until in the Monotreme the epicoracoid is entirely excluded from the glenoid; in the marsupial it is only recognized as a thin cellular sheet in the early embryo which soon disappears; and no trace of it is found in the other groups of mammals unless it be, as suggested by Broom ('12), represented by the coraco-clavicular ligament. 
Thus, while there has been great diversity of opinion with regard to the homology of the anterior element and the coracoid process, the main group of workers agree that the so-called subcoracoid is the homologue of the coracoidal element variously known as the true coracoid, posterior coracoid, metacoracoid, or simply the coracoid. If this be true, the coracoid in the pig may be described as a glenoid-sharing portion, which is undoubtedly the homologue of the subcoracoid of man and also the sole remaining evidence of the true or posterior coracoid which in the lower groups (birds, reptiles, amphibians) extends to and articulates with the sternum. While in most mammals this coracoid is represented by a coracoid process as well as by its epiphysis (the subcoracoid), in the pig and in the ungulates generally the resorption of the coracoid bar has been complete, leaving only the subcoracoid, which is as we would expect, since the subcoracoid has the definite function of helping to form the articular surface for the humerus.

It has been shown by Broom in various papers that in a number of marsupials the embryo or foetus has a distinct coracoid extending from the scapula to the sternum. As development proceeds a process of absorption commences in the middle of this coracoidal bar and proceeds in each direction, until, on the one hand, the entire sternal end of the embryonic coracoid disappears, while on the other, the absorption stops just short of the scapula, leaving the well-known coracoid process of the adult marsupial and of course its epiphysis, the subcoracoid.

It is not at all difficult to see how, if this process of absorption were in the pig to proceed as completely scapulaward as sternalward, that the actual condition as found in the Suidae would result. That this degeneration should be incomplete in most mammals, leaving a coracoid process, and complete in the pigs, therefore not leaving a coracoid process, is neither unusual nor unexpected, for degeneration processes are apt to be irregular, and, further, this condition has its exact counterpart at the sternal end of the coracoid, where in the majority of mammals no trace of the coracoid is left, yet in the rodents a coracoid process is left on the sternum, because of an incomplete de- 
generation at this end. To sum up, in the Amphibia, Reptilia, Aves, and Monotremes there is a coracoid extending throughout life from the sternum to the scapula. In the Placental mammals absorption of the coracoidal bar from the middle portion in each direction results in the complete disappearance of the sternal half of the coracoid, the rodents excepted; while the scapular half of the coracoid does not completely disappear, but is represented by its distal end, the coracoid process. The Ungulates constitute an exception to this, in which the entire coracoid bar disappears, leaving no trace at either end, excepting always its epiphysis incorporated into the glenoid, and known as the subcoracoid.

\section{CONCLUSIONS}

1. The coracoid process is absent in the pig.

2. The subcoracoid is present and ossifies from a single center.

3. The subcoracoid is a glenoid-sharing portion and is the homologue of the like-named structure in man.

4. The subcoracoid has all the characteristics of an epiphysis, and may be the epiphysis of the posterior or true coracoid of the lower forms.

\section{LITERATURE CITED}

Broom, R. 1899 On the development and morphology of the marsupial shouldergirdle. Trans. Roy. Soc. Edinb., vol. 39, pt. 3.

1912 The morphology of the coracoid. Anat. Anz., Bd. 41, s. 625-631.

Cunningham 1916 Text-book of anatomy. 4th ed.

Gregory, W. K. 1915 Present status of the problem of the origin of the Tetrapoda. Ann. N. Y. Acad. Se., vol. 26.

1917 a From a private communication to the author.

$1917 \mathrm{~b}$ From a private communication to the author.

Howes, G. B. 1893 On the coracoid of the terrestrial animals. Proc. Zool. Soc. Lon., June, 1893.

LYDEKKER, R. 1893 Notes on the coracoidal element in adult sloths, with remarks on its homology. Proc. Zool. Soc. Lon., 1893. 
Resumido por el autor, Harvey Ernest Jordan.

Estudios sobre la estructura estriada de los músculos.

IV. Discos intercalados en el músculo estriado voluntario.

El autor describe discos intercalados típicos en los músculos de la pierna del hombre, semejantes a los sencillos discos en "forma de banda" que existen en el músculo cardíaco. La presencia de tales discos en el músculo estriado voluntario está de acuerdo con la hipótesis que les supone como los representantes de bandas de contracción irreversibles que se han modificado, y, además, susministra una prueba adicional en contra de su interpretación como los limites de las células del miocardio. El autor resume y discute los cambios estructurales que sufre la fibra muscular estriada durante la contracción, los cuales se manifiestan por cambios en sus reacciones colorantes.

Translation by José F. Nonidez

Columbia University 